\title{
Analisis Beban Kerja Fisik dan Mental Pada Operator Contact Center (Studi Kasus : PT. XYZ Samarinda)
}

\author{
Lina Dianati Fathimahhayati $^{* 1}$, Lilis Anggrainy ${ }^{2}$, Willy Tambunan ${ }^{3}$ \\ ${ }^{1,2,3}$ Program Studi Teknik Industri, Fakultas Teknik Universitas Mulawarman \\ Jalan Sambaliung No. 9, Kampus Gunung Kelua, Samarinda 75119 \\ e-mail: ${ }^{* 1}$ linadianatif@gmail.com, ${ }^{2}$ anggrainylilis@ gmail.com, ${ }^{3}$ wil_ly22@yahoo.co.id
}

\begin{abstract}
Abstrak
Tuntutan perkerjaan operator contact center PT. XYZ Samarinda untuk selalu ramah kepada pelanggan dalam keadaan apapun dan harus fokus dalam bekerja dapat menimbulkan beban kerja mental. Selain itu operator contact center harus bekerja monoton dengan keadaan duduk di depan komputer dalam waktu 8 jam dapat saja menimbulkan beban kerja fisik. Penelitian ini bertujuan menganalisis beban kerja fisik dan mental pada operator contact center dan memberikan rekomendasi perbaikan untuk meningkatkan produktivitas dan kenyamanan saat bekerja. Pengukuran beban kerja fisik dilakukan menggunakan metode pengukuran Cardiovascular Load (\%CVL) pada saat bekerja. Sedangkan pengukuran beban kerja mental dilakukan menggunakan metode NASA-TLX dengan membagikan kuesioner kepada 9 operator contact center selama 10 hari. Hasil penelitian menunjukkan bahwa ratarata beban kerja fisik operator contact center adalah 13,5\%, yang menunjukkan bahwa beban kerja fisik operator contact center termasuk kategori ringan. Sedangkan rata-rata beban kerja mental operator contact center adalah 65 , yang berarti bahwa beban kerja mental dalam kategori sedang. Rekomendasi perbaikan yang dapat diberikan antara lain melakukan cara duduk yang benar, melakukan perbaikan tata letak AC agar lingkungan kerja menjadi nyaman dan menggunakan kursi kerja ergonomis. Selain itu perlu dibangun hubungan yang baik yaitu dengan memahami gaya komunikasi antar pekerja agar tidak terjadi kesalahpahaman, melakukan perayaan kecil, olahraga atau rekreasi bersama, dan mengadakan Training ESQ untuk menyeimbangkan emosi dan kecerdasan.
\end{abstract}

Kata kunci: beban kerja fisik, beban kerja mental, CVL, NASA-TLX, operator contact center

\begin{abstract}
The work requirements of the contact center operator in PT. XYZ Samarinda to always be friendly to customers in any circumstances and have to focus on work is likely to cause mental workload. In addition, the contact center operator must work monotonously by sitting in front of the computer within 8 hours can cause physical workload. This study aims to analyse the physical and mental workload of the contact center operators and suggest recommendations to improve productivity and comfort while working. Measurement of physical workload is done using the \%CVL measurement method at work. While the measurement of mental workload was carried out using the NASA-TLX method by distributing questionnaires to 9 contact center operators for 10 days. The results showed that the average physical workload of contact center operators was $13.5 \%$, indicating that the physical workload of contact center operators is in the low category, which means there is no significant burden. While the average mental workload of contact center operators is 65, meaning tha, the mental workload is in the moderate category. Recommendations for improvements that can be given are doing the right way to sit, making improvements to the layout of the air conditioner so that the work environment becomes comfortable and using an ergonomic work chair. In addition it is necessary to build a good relationship that is by understanding the communication style between workers so that misunderstandings cannot
\end{abstract}


be occured, conduct small celebrations, recreation, and hold ESQ Training to balance emotions and intelligence.

Keywords: phiscal workload, mental workload, CVL, NASA-TLX, contact center operator

\section{PENDAHULUAN}

Setiap aktivitas atau pekerjaan yang dilakukan suatu pekerja pasti selalu mempunyai suatu beban kerja. Beban kerja tersebut terdiri dari dua macam yaitu beban kerja fisik dan beban kerja mental. Intensitas pekerjaan yang terlalu tinggi memungkinkan penggunaan energi berlebihan sehingga menimbulkan kelelahan fisik. Sebaliknya, intensitas pekerjaan yang terlalu rendah memungkinkan munculnya rasa jenuh atau bosan. Tingkat intensitas yang optimum ada di antara kedua batasan ekstrim tersebut dan tentunya berbeda-beda untuk tiap individu (Tarwaka dan Sudiajeng, 2004).

Beban kerja fisik biasanya dapat dapat dilihat secara langsung, misalnya kelelahan, menurunnya tingkat produktivitas pekerja, kesalahan-kesalahan yang terjadi, dan lain- lain. Penanganannya dapat diambil tindakan secara langsung seperti istirahat sejenak dari pekerjaan, pemberian waktu makan dan minum, dan lain-lain. Hasil dari penanganannya pun dapat dirasakan secara langsung dan membutuhkan waktu yang relatif singkat. Sedangkan beban kerja mental tidak dapat dilihat secara kasat mata, dan tak jarang kita tidak menyadari bahwa sebenarnya seorang pekerja mengalami beban kerja mental yang berlebih. Beban kerja mental bersifat subjektif dan tentunya berbeda bentuknya pada setiap pekerja. Penanganan beban kerja mental tidaklah semudah penanganan beban kerja fisik. Hal ini berkaitan dengan psikis seseorang, maka diperlukan pendekatan tersendiri sehingga diketahui apa penyebab beban kerja mental tersebut sehingga dapat diatasi. Penilaian beban kerja mental juga tidaklah semudah menilai beban kerja fisik. Pekerjaan yang bersifat mental sulit diukur melalui perubahan fungsi faal tubuh. Setiap aktivitas mental akan selalu melibatkan unsur persepsi, interpretasi dan proses mental dari suatu informasi yang diterima oleh organ sensoris untuk mengambil suatu keputusan atau proses mengingat informasi yang lampau.

Operator contact center PT. XYZ Samarinda adalah petugas yang bekerja di suatu pusat pelayanan jarak jauh yang dilakukan melalui media komunikasi telepon, dimana pelanggan dapat berkomunikasi secara real-time dengan petugas pelayanan. Sikap paling utama yang harus dimiliki operator adalah ramah dan baik. Namun pelanggan sendiri memiliki berbagai karakter dan sifat yang berbeda-beda, ada yang kritis, emosional, suka mencela, serta lambat dalam mengerti akan suatu informasi yang disampaikan oleh operator. Operator juga dituntut ramah kepada customer dalam keadaan apapun dan terus mendengarkan masalah customer setiap harinya. Hal tersebut dapat menyebabkan munculnya stress kerja dan dampak psikologis yang mengakibatkan tingginya tingkat turn-over operator contact center.

Berdasarkan permasalahan tersebut dilakukan penelitian mengenai beban kerja mental dan fisik operator contact center pada PT. XYZ dengan menggunakan metode Nasa-TLX (Task Load Index) dan metode pengukuran \%CVL. Nasa-TLX (Task Load Index) merupakan metode yang digunakan untuk menganalisis beban kerja mental yang dihadapi oleh pekerja yang harus melakukan berbagai aktivitas dalam pekerjaannya. Sedangkan pengukuran beban kerja fisik dilakukan dengan menghitung \%CVL. Dengan metode NASA-TLX dan pengukuran \%CVL dapat diperoleh beban kerja mental dan fisik operator contact center yang berada di PT. 
XYZ Samarinda, sehingga diperoleh usulan perbaikan untuk mengatasi beban kerja mental dan fisik yang ada pada operator contact center PT. XYZ Samarinda.

\section{METODE PENELITIAN}

Workload atau beban kerja merupakan usaha yang harus dikeluarkan oleh seseorang untuk memenuhi "permintaan" dari pekerjaan tersebut. Beban kerja yang dimaksud adalah ukuran (porsi) dari kapasitas operator yang terbatas yang dibutuhkan untuk melakukan kerja tertentu. Beban kerja adalah jumlah kegiatan yang harus diselesaikan oleh seseorang ataupun sekelompok orang selama periode waktu tertentu dalam keadaan normal (Tarwaka, 2015).

Pengukuran beban kerja fisik operator contact center dilakukan menggunakan metode pengukuran \%CVL. Sedangkan pengukuran beban kerja mental dilakukan menggunakan metode NASA-TLX dengan membagikan kuesioner kepada 9 operator contact center selama 10 hari. Penentuan klasifikasi beban kerja fisik berdasarkan peningkatan denyut nadi kerja yang dibandingkan dengan denyut nadi maksimum karena beban kardiovaskuler (cardiovasculair load $=\% \mathrm{CVL}$ ) dihitung dengan Persamaan 1.

$\% C V L=\frac{100 \times(\text { Denyut nadi kerja-Denyut nadi istirahat }}{\text { Denyut nadi maksimum-Denyut nadi istirahat }}$

Dimana denyut nadi maksimum adalah (220-umur) untuk laki-laki dan (200umur) untuk wanita. Dari hasil perhitungan \%CVL tersebut kemudian dibandingkan dengan klasifikasi yang telah ditetapkan pada Tabel 1.

Tabel 1 Kategori beban kerja berdasarkan \%CVL

\begin{tabular}{cccl}
$\begin{array}{c}\text { Tingkat } \\
\text { Pembebanan }\end{array}$ & $\begin{array}{c}\text { Kategori } \\
\text { \%CVL }\end{array}$ & Nilai \%CVL & \multicolumn{1}{c}{ Keterangan } \\
\hline 0 & Ringan & $<30 \%$ & $\begin{array}{l}\text { Tidak terjadi pembebanan } \\
\text { yang berarti }\end{array}$ \\
\hline 1 & Sedang & $30 \mathrm{s.d}<60 \%$ & $\begin{array}{l}\text { Pembebanan sedang dan } \\
\text { mungkin diperlukan perbaikan }\end{array}$ \\
\hline 2 & Agak Berat & $60 \mathrm{s.d}<80 \%$ & $\begin{array}{l}\text { Pembebanan agak berat } \\
\text { dan diperlukan perbaikan }\end{array}$ \\
\hline 3 & Berat & $80 \mathrm{s.d} 100 \%$ & $\begin{array}{l}\text { Pembebanan berat dan } \\
\text { harus sesegera mungkin } \\
\text { dilakukan tindakan perbaikan; } \\
\text { hanya boleh bekerja pada waktu } \\
\text { yang singkat }\end{array}$ \\
\hline 4 & Sangat Berat & $>100 \%$ & $\begin{array}{l}\text { Pembebanan sangat berat dan } \\
\text { stop bekerja sampai dilakukan }\end{array}$ \\
\hline
\end{tabular}

Metode NASA-TLX merupakan metode yang digunakan untuk menganalisis beban kerja mental yang dihadapi oleh pekerja yang harus melakukan berbagai aktivitas dalam pekerjaannya. Metode ini di kembangkan oleh Sandra G. Hart dari NASA-Ames Research Center dan Lowell E. Staveland dari San Jose State University pada tahun 1981 berdasarkan munculnya kebutuhan pengukuran subjektif yang terdiri dari skala sembilan faktor (kesulitan tugas, tekanan waktu, jenis 
aktivitas, usaha fisik, usaha mental, performansi, frustasi, stress dan kelelahan). Dari sembilan faktor ini disederhanakan lagi menjadi 6 yaitu Mental Demand (MD), Physical Demand (PD), Temporal Demand (TD), Performance (P), Effort (E), Frustation Level (FR). NASA-TLX (Task Load Index) adalah suatu metode pengukuran beban kerja mental secara subjektif (Hart and Staveland, 1981).

Langkah-langkah pengukuran dengan menggunakan NASA TLX adalah sebagai berikut (Hancock \& Meshkati, 1988) :

1. Pembobotan

Pada bagian ini responden diminta untuk memilih salah satu dari dua indikator yang dirasakan lebih dominan menimbulkan beban kerja mental terhadap pekerjaan tersebut. Kuesioner NASA-TLX yang diberikan berupa perbandingan berpasangan. Dari kuesioner ini dihitung jumlah tally dari setiap indikator yang dirasakan paling berpengaruh. Jumlah tally menjadi bobot untuk tiap indikator beban mental. Perbandingan indikator NASA TLX dapat dilihat pada Gambar 1.

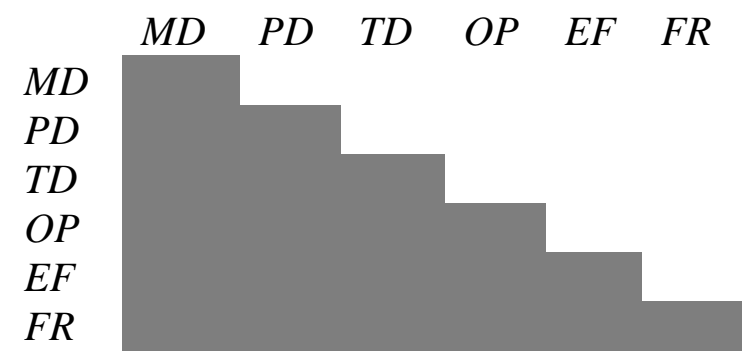

Gambar 1. Perbandingan indikator beban kerja mental

2. Pemberian Rating

Pada bagian ini responden diminta memberi rating 0 sampai 100 terhadap keenam indikator beban mental. Rating yang diberikan adalah subjektif tergantung pada beban mental yang dirasakan oleh responden tersebut. Untuk mendapatkan skor beban mental NASA-TLX, bobot dan rating untuk setiap indikator dikalikan kemudian dijumlahkan dan dibagi dengan 15.

3. Menghitung Nilai Produk

Diperoleh dengan mengalikan rating dengan bobot faktor untuk masing-masing deskriptor. Dengan demikian dihasilkan 6 nilai produk untuk 6 indikator (MD, PD, TD, CE, FR, EF) dapat dilihat pada Persamaan 2.

Produk $=$ Rating $*$ Bobot kerja

4. Menghitung Weighted Workload (WWL)

Diperoleh dengan menjumlahkan keenam nilai produk, dapat dilihat pada Persamaan 3.

$W W L=\sum$ produk

5. Menghitung rata-rata WWL

Diperoleh dengan membagi WWL dengan jumlah bobot total, dapat dilihat pada Persamaan 4.

Skor $=\left(\sum\right.$ produk $) / 15$

6. Interpretasi Skor

Hart dan Staveland (1988) menjelaskan dalam teori NASA-TLX, skor beban kerja yang diperoleh dapat diintepretasikan sebagai berikut:

1. Nilai skor $>80$ menyatakan beban pekerjaan berat,

2. Nilai skor 50-70 menyatakan beban pekerjaan sedang, dan

3. Nilai skor $<50$ menyatakan beban pekerjaan ringan. 
Output yang dihasilkan dari pengukuran dengan NASA-TLX ini berupa tingkat beban kerja mental yang dialami oleh pekerja.

\section{HASIL DAN PEMBAHASAN}

\subsection{Hasil Pengukuran Beban Kerja Fisik}

Hasil pengukuran \%CVL rata-rata seluruh operator selama 10 hari dapat dilihat pada Gambar 2.

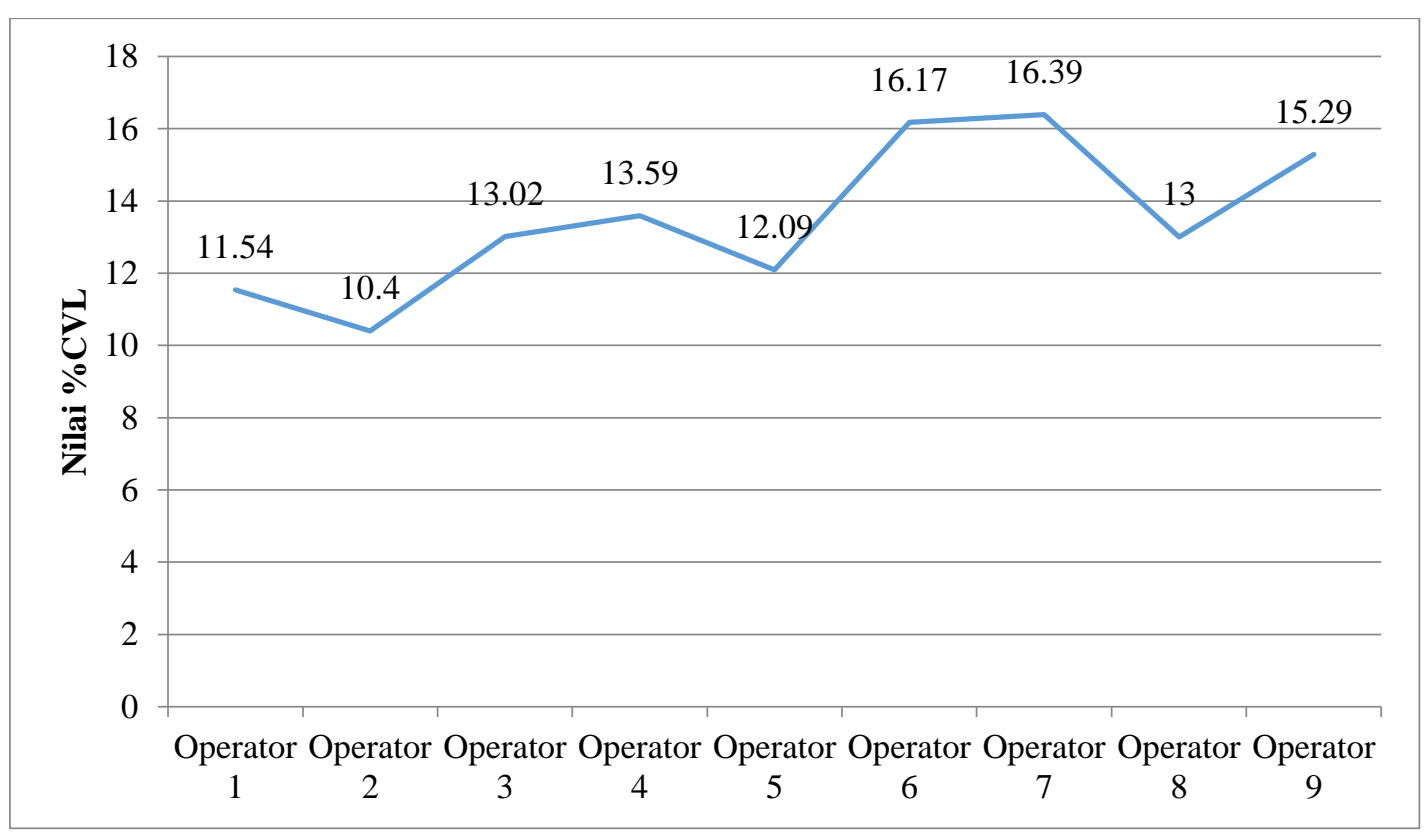

Gambar 2. Rata-rata nilai beban kerja fisik operator contact center

Berdasarkan Gambar 2 didapatkan nilai \%CVL rata-rata seluruh operator $<30 \%$ yang berarti bahwa beban kerja fisik ringan. Walaupun tergolong ringan akan tetap ada beban kerja fisik yang dirasakan seluruh operator. Menurut Pirade, dkk (2013), pekerjaan yang dilakukan hanya dengan duduk hampir 8 jam membuat operator akan mendapatkan risiko yang buruk seperti masalah nyeri punggung bagian bawah mekanik kronik.

\subsection{Hasil Pengukuran Beban Kerja Mental}

Hasil pengukuran NASA-TLX rata-rata seluruh operator dapat dilihat pada Gambar 3. Berdasarkan Gambar 3 didapatkan nilai NASA-TLX rata-rata seluruh operator berada pada rentang 50-70 yang berarti bahwa beban kerja mental tergolong sedang. Seluruh operator merasakan tuntutan mental seperti saat pelayanan pada customer yang dituntut untuk selalu ramah dan sopan walaupun terkadang customer berbicara tidak ramah dan tidak sopan. Hal ini sejalan dengan penelitian Ramadhania (2010) tentang pengukuran beban kerja psikologis karyawan call center menggunakan metode NASA-TLX. Hasil dari penelitian ini ialah faktor yang paling dominan terletak pada indikator kebutuhan mental (mental demand). Hal tersebut menjadikan operator call center harus memiliki tanggung jawab yang besar terhadap kepuasan pelanggan pada perusahaan. Selain itu pada saat melakukan pekerjaan 
dibutuhkan konsentrasi dan harus fokus, karena harus mendengarkan keluhan, permintaan serta informasi dari pelanggan maupun pihak perusahaan.

Seluruh operator juga merasakan kejenuhan dan kebosanan pada pekerjaan yang monoton ini. Stres kerja sendiri dapat timbul sebagai akibat dari tekanan atau ketegangan yang bersumber dari ketidakselarasan antara seseorang dengan lingkungannya, dengan kata lain apabila sarana dan tuntunan tugas tidak selaras dengan kebutuhan dan kemampuan individu tersebut maka individu akan mudah stres.

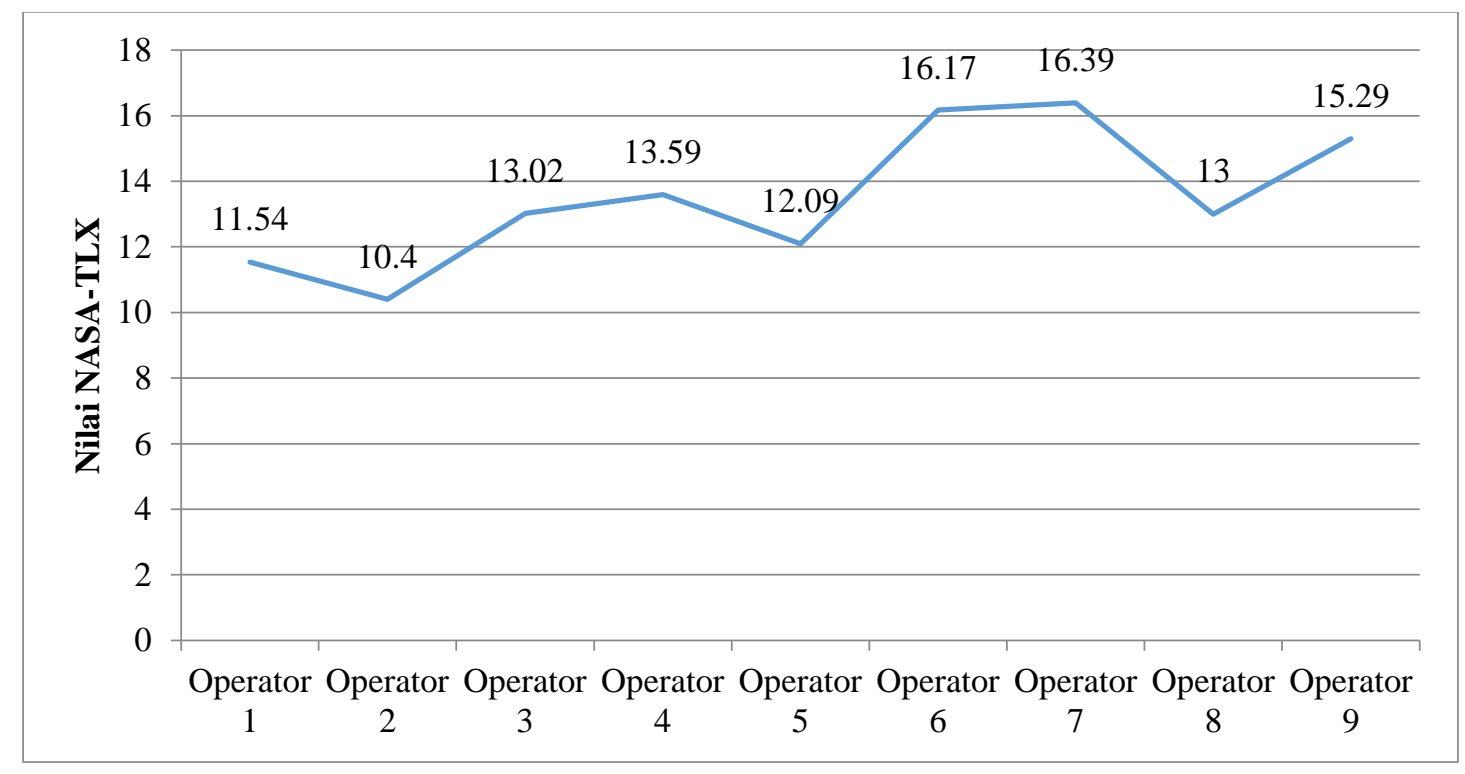

Gambar 3 Rata-rata nilai beban kerja mental operator contact center

\subsection{Rekomendasi Perbaikan Beban Kerja Fisik}

Usulan atau rekomendasi perbaikan untuk beban kerja fisik berdasarkan hasil penelitian yang telah dilakukan adalah sebagai berikut:

a. Melakukan pencegahan terkena risiko yang disebabkan karena duduk terlalu lama yaitu dengan melakukan cara duduk yang benar yaitu posisi duduk pada otot rangka, posisi duduk pada tulang belakang, dan posisi duduk pada pinggang hendaknya harus dapat ditahan oleh sandaran kursi agar terhindar dari nyeri dan cepat lelah, posisi kaki harus berada pada alas kaki yang dapat bebas bergerak dan fleksibel, dan juga posisi duduk harus relaksasi sehingga tekanan tulang belakang tidak meningkat dan tidak menjadi kaku.

b. Perbaikan tata letak AC agar lingkungan kerja menjadi nyaman, dan

c. Melakukan penggantian kursi yang digunakan, menggunakan kursi kerja ergonomis akan membuat badan terasa nyaman. Kriteria umum yang harus diperhatikan dalam memilih kursi kerja untuk memenuhi standar sebagai kursi ergonomis yaitu sebagai berikut:

1) Ketinggian tempat duduk, berkisar antara 16-21 inci $(40-53 \mathrm{~cm})$ dari lantai, dan harus dapat disetel oleh pemakai (adjustable),

2) Lebar dan kedalaman tempat duduk, standar lebar jok kursi adalah 17-20 inci (43-51 cm) dengan kedalaman (selisih tinggi dari bagian depan hingga 
bagian yang menyangga pantat pada tempat duduk atau jok) antara 2-4 inci $(5-10 \mathrm{~cm})$,

3) Lumbar support, kursi yang ergonomis harus memiliki setelan penyangga pinggang sesuai kebutuhan spesifik masing-masing pengguna,

4) Sandaran punggung (backrest) dengan lebar antara 12-19 inci $(30,5-48,2 \mathrm{~cm})$,

5) Material lapisan kursi dari bahan yang berpori dan dapat mendukung sirkulasi udara sehingga tidak menimbulkan efek negatif apabila digunakan dalam waktu lama,

6) Sandaran lengan (armrest) yang dapat disetel,

7) Swivel yaitu penyangga putar kursi harus dapat memutar dengan mudah sehingga pengguna dapat meraih sesuatu tanpa harus terlalu merentangkan tubuhnya dengan sudut yang dapat memicu terjadinya cedera.

Selain 7 kriteria umum terdapat pula penambahan penyangga kaki (footrest) agar kaki tidak tegang. Contoh kursi dan penggunaannya dapat dilihat pada Gambar 4.

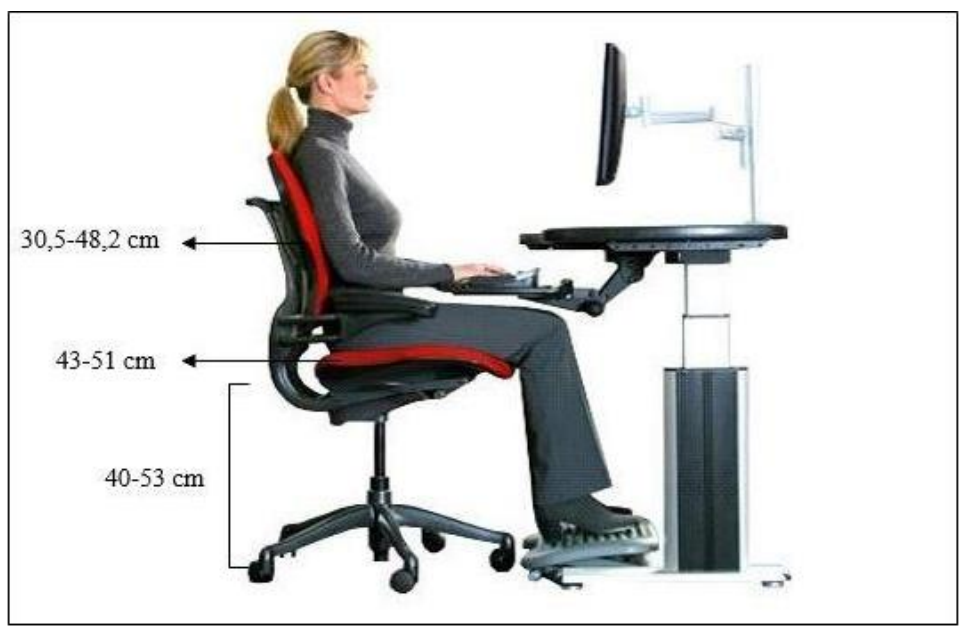

Gambar 4. Sketsa kursi ergonomis

\subsection{Rekomendasi Perbaikan Beban Kerja Mental}

Adapun usulan atau rekomendasi perbaikan untuk beban kerja mental berdasarkan hasil penelitian yang telah dilakukan adalah sebagai berikut:

a. Membangun hubungan yang baik yaitu dengan memahami gaya komunikasi antar pekerja agar tidak terjadi kesalahpahaman,

b. Melakukan perayaan kecil, berolahraga atau berekreasi bersama untuk menciptakan keharmonisan dan juga membuat rileks pikiran, dan

c. Mengadakan Training ESQ (Emotional Spiritual Quostients). ESQ merupakan sebuah teori yang menyeimbangkan emosional dan kecerdasan, dikembangkan oleh Ary Ginanjar Agustian. Terdapat lima unsur utama yang membangun kecerdasan emosi yaitu sebagai berikut:

1) Mengenali emosi diri. Mengenali emosi diri sendiri merupakan suatu kemampuan untuk mengenali perasaan sewaktu perasaan itu terjadi. Kesadaran diri memang belum menjamin penguasaan emosi, namun merupakan salah satu prasyarat penting untuk mengendalikan emosi sehingga individu mudah menguasai emosi. 
2) Mengelola emosi. Mengelola emosi merupakan kemampuan individu dalam menangani perasaan agar dapat terungkap dengan tepat atau selaras, sehingga tercapai keseimbangan dalam diri individu. Menjaga agar emosi yang merisaukan tetap terkendali merupakan kunci menuju kesejahteraan emosi.

3) Memotivasi diri sendiri, kemampuan memotivasi diri merupakan kemampuan mendorong dan mengarahkan segala daya upaya dirinya bagi pencapaian tujuan, keinginan dan cita-citanya. Peran memotivasi diri yang terdiri atas antusiasme dan keyakinan pada diri seseorang akan sangat produktif dan efektif dalam segala aktivitasnya.

4) Mengenali emosi orang lain, Kemampuan untuk mengenali emosi orang lain disebut juga empati. ndividu yang memiliki kemampuan empati lebih mampu menangkap sinyal-sinyal sosial yang tersembunyi yang mengisyaratkan apaapa yang dibutuhkan orang lain sehingga ia lebih mampu menerima sudut pandang orang lain, peka terhadap perasaan orang lain dan lebih mampu untuk mendengarkan orang lain.

5) Membina hubungan. Kemampuan dalam membina hubungan merupakan suatu keterampilan yang menunjang popularitas, kepemimpinan dan keberhasilan antar pribadi. Keterampilan dalam berkomunikasi merupakan kemampuan dasar dalam keberhasilan membina hubungan. Individu sulit untuk mendapatkan apa yang diinginkannya dan sulit juga memahami keinginan serta kemauan orang lain.

\section{KESIMPULAN}

Hasil penelitian menunjukkan bahwa rata-rata beban kerja fisik operator contact center PT. XYZ Samarinda adalah 13,5\%. Hasil tersebut menunjukkan bahwa beban kerja fisik operator contact center termasuk kategori ringan yang artinya tidak terjadi pembebanan yang berarti. Sedangkan rata-rata beban kerja mental operator contact center adalah 65 . Berdasarkan hasil tersebut maka nilai beban kerja mental operator contact center dalam kategori sedang.

Rekomendasi perbaikan yang dapat diberikan terhadap perolehan beban kerja fisik yang dirasakan oleh operator contact center adalah melakukan pencegahan terkena risiko yang disebabkan karena duduk terlalu lama yaitu dengan melakukan cara duduk yang benar yaitu posisi duduk pada otot rangka, posisi duduk pada tulang belakang, dan posisi duduk pada pinggang hendaknya harus dapat ditahan oleh sandaran kursi agar terhindar dari nyeri dan cepat lelah, posisi kaki harus berada pada alas kaki yang dapat bebas bergerak dan fleksibel, dan juga posisi duduk harus relaksasi sehingga tekanan tulang belakang tidak meningkat dan tidak menjadi kaku. Selain itu perlu melakukan perbaikan tata letak AC agar lingkungan kerja menjadi nyaman dan menggunakan kursi kerja ergonomis akan membuat badan terasa nyaman. Rekomendasi usulan yang dapat diberikan terhadap perolehan beban kerja mental yang dirasakan oleh operator contact center adalah membangun hubungan yang baik yaitu dengan memahami gaya komunikasi antar pekerja agar tidak terjadi kesalahpahaman, melakukan perayaan kecil, berolahraga atau berekreasi bersama untuk menciptakan keharmonisan dan juga membuat pikiran rileks, dan mengadakan Training ESQ (Emotional Spiritual Quostients) untuk menyeimbangkan emosi dan kecerdasan. 


\section{DAFTAR PUSTAKA}

Hancock, P.A., dan Meshkati, N., 1988, Human Mental Workload, University Of South California, CA

Hart, S. G., dan Staveland, L. E., 1988, Development of Nasa-Task Load Index (Nasa-TLX); Result of Empirical and Theoritical Research, Nasa-Ames Research Center, Moffet Field, CA.

Pirade, A., Angliadi, E., dan Sengkey, L.S., 2013, Hubungan Posisi dan Lama Duduk dengan Nyeri Punggung Bawah (NPB) Mekanik Kronik pada Karyawan Bank, Jurnal Biomedik (JBM), Volume 5, Nomor 1

Ramadhania, N., 2015, Pengukuran Beban Kerja Psikologis Karyawan Call Center Menggunakan Metode NASA-TLX (Task Load Index) Pada PT XYZ, Jurnal Sains dan Teknologi, ISSN: 2407-1846

Tarwaka, Sudiajeng, L, 2004, Ergonomi Untuk Keselamatan, Kesehatan Kerja dan Produktivitas, Surakarta, UNIBA PRESS.

Tarwaka, 2015, Dasar-dasar Pengetahuan Ergonomi dan Aplikasi di Tempat Kerja, Harapan Press, Surakarta. 